Research Paper:

\title{
Lifestyle Factors Related to Dysmenorrhea Among High School Students
}

\author{
Fatemeh Moghaddam Tabrizi ${ }^{1}$, Samira Barjasteh $^{2}$, Elham Rezaei $^{2^{*}} \mathbb{D}$
}

1. Reproductive Health Research Center, Urmia University of Medical Sciences, Urmia, Iran.

2. Department of Midwifery, School of Nursing and Midwifery, Urmia University of Medical Sciences, Urmia, Iran

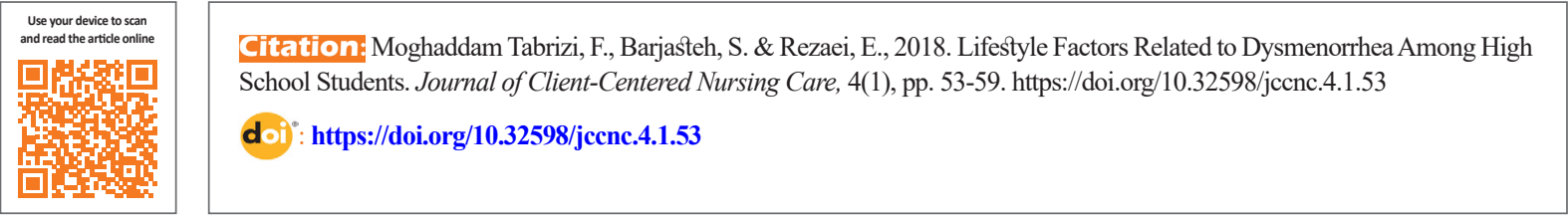

Funding: See Page 58

(c) Copyright: The Author(s)

Article info:

Received: 28 May 2017

Accepted: 05 Sep 2017

Available Online: 01 Feb 2018

Keywords:

Life style, Cross-sectional study, Dysmenorrhea

\begin{abstract}
A B S T RA C T
Background: Menstrual disorders or dysmenorrhea are common health problems in women. Presumably, lifestyle factors could be associated with this condition. This study aimed to evaluate dysmenorrhea and its related lifestyle factors in the high school students of Urmia City, Iran.

Methods: In this descriptive cross-sectional study, 1475 students of all girls' high schools were recruited by stratified sampling from urban areas of Urmia City, Iran in 2016. The relevant data were gathered by a researcher-made questionnaire and Visual Analogue Scale (VAS) to assess women's dysmenorrhea in the last 3 menstrual cycles. Then the obtained data were analyzed by ANOVA, Chi-square, Pearson's contingency coefficient, and Gamma in SPSS-PC V. 23.

Results: The prevalence of dysmenorrhea was $93.7 \%$ among study participants. Significant and direct relationships were observed between dysmenorrhea and lifestyle (diet $[\mathrm{P}<0.001]$, exercise $[\mathrm{P}<0.001]$, and sleep status $[\mathrm{P}<0.001])$, except for the number of family members and duration of menstrual cycle. In addition, there was significant and negative correlation between dysmenorrhea and demographic factors (BMI $[\mathrm{P}<0.001]$, age [ $\mathrm{P}<0.001]$, birth order $[\mathrm{P}<0.001]$ ).

Conclusion: Dysmenorrhea is highly prevalent and may be related to lifestyle factors among high school students. High school teachers should be aware of these facts, and proper information about lifestyle should be provided for girls suffering from dysmenorrhea symptoms.
\end{abstract}

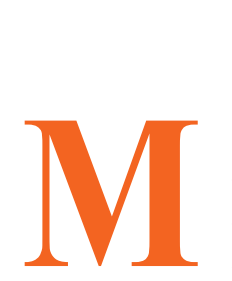

\section{Background}

enstrual disorders or premenstrual syndrome is a major and common health difficulty among adolescent girls because it influences not only their future fertility, but also their mental health and quality of life. It is the most common gynecological problem worldwide, also an important cause of the students' absence from the school (Beiranvand et al. 2016; Moghadam et al. 2016; Sultan, Gaspari \& Paris 2012).

The prevalence of menstrual pain has been estimated to be $21 \%$ to $85 \%$ (Beiranvand et al. 2016; Harlow \& Campbell 2004; Moghadam et al. 2016; Unsal et al. 2010) in different studies. Previous epidemiologic

\section{* Corresponding Author:}

Elham Rezaei, MSc. Student

Address: Department of Midwifery, School of Nursing and Midwifery, Urmia University of Medical Sciences, Urmia, Iran.

Tel: +98 (914) 4633116

E-mail: rezai520@yahoo.com 
studies have reported high prevalence rates of dysmenorrhea ranging from $43 \%$ to $91 \%$ in adolescent girls (Sultan et al. 2012).

Previous studies have also shown that lifestyle factors, including physical activity and diet, are related to this condition in adolescents (French 2008). However, these findings are found on high school and university students, and few studies have targeted younger adolescents. Studies on the prevalence and severity of menstrual pain have demonstrated that many factors are related to this disorder including younger age, low Body Mass Index (BMI), smoking, early menarche, prolonged or aberrant menstrual flow, premenstrual somatic complaints, pelvic infections, previous sterilization, somatization, psychological disorders, genetics, and history of sexual assault (Latthe et al. 2006; Tonini 2002).

Some studies have shown that women with early menarche experience more pain during menstruation (Harlow \& Campbell 2004), while some other studies have detected no association between the age at menarche and dysmenorrhea (Weissman et al. 2004). Certain types of diets such as low fat vegetarian diets have been reported to reduce the intensity of pain during menstruation in one study (Barnard et al. 2000). Some studies have shown that exercise might decrease menstrual pain (Chen \& Hu 2018; Travers et al. 2018). Some studies have demonstrated a significant positive association between pain and stress (Alonso \& Coe 2001; Wang et al. 2004). Some other studies have reported that smokers experience menstrual pain more than non-smokers. In contrast, one study showed that smokers experience less pain. Women who use oral contraceptives have less menstrual pain (Haidari et al. 2011; Kazama, Maruyama \& Nakamura 2015).

A number of studies have targeted young women, including older adolescents (i.e. high school students), as well as older women, but only a few studies have targeted younger adolescents, i.e. junior high school students (aged 12-15 years). Due to the limited research in this field, we decided to conduct a research in this area. Thus, we studied the prevalence of dysmenorrhea and its related lifestyle factors in high school students.

\section{Materials and Methods}

In this descriptive cross-sectional study, 1475 students of all high school girls of Urmia, with no known disease that could affect their menstrual status, were recruited in 2016. Stratified sampling was used in urban areas of the city (Districts 1 and 2) based on their financial situation (high, moderate, and low); Then, a list of high schools was prepared. Next, a number of high schools were randomly selected in each economic zone, the number of classes in each educational grade was determined and the students were selected.

Students with primary dysmenorrhea (according to self-report and history of menstrual cycles) were included, and those with secondary dysmenorrhea were excluded from the study. Two questionnaires adopted in the present study were a researcher-made (individual and menstrual characteristics and lifestyle data including diet, exercise, and sleep status of students) and the Visual Analogue Scale (VAS) to assess dysmenorrhea in the last 3 menstrual cycles. Because of the frequent use of this scale in dysmenorrhea, the researchers decided to use VAS in this study (Azimi \& Abrishami 2018). After preparation of the questionnaires and obtaining authorization and approval from the Nursing and Midwifery School and Ethics Committee of Urmia University of Medical Sciences, the eligible students were selected.

All participants were informed about the purpose and protocol of this study. They were informed that participation in the study was voluntary and they could refuse to participate at any time without having any negative impact on the services delivered to them. The Ethics Committee of Urmia University of Medical Sciences approved the research proposal (1394-01-42-2017). Informed consent was obtained from the students who agreed to participate in the study. So the students were asked to evaluate the physical pain in accordance with the date of menarche and the last three consecutive menstrual periods by using VAS. It is a subjective pain appraisal method whish its reliability and validity for the assessment of dysmenorrhea has been evaluated in several domestic and foreign studies. Scores below 4 indicate mild dysmenorrhea, between 4-6 show moderate dysmenorrhea, and more than or equal to 7 are suggestive of severe dysmenorrhea (Azimi \& Abrishami 2018).

In this study, dysmenorrhea was considered as the pain that affects a person's life and was difficult to tolerate (Haidari et al. 2011; Kazama et al. 2015). SPSS-PC V. 23 was employed to analyze the results using the descriptive and analytical statistics including frequency tables, ANOVA, Chi-square, Pearson's contingency coefficient and Gamma. In this study, 24 students were excluded because their questionnaires were incomplete or they were willing to withdraw from the study.

\section{Results}

The demographic and menstrual characteristics and lifestyle data of the 1451 participants are summarized 
in Tables 1 and 2. ANOVA and Chi-square showed that participants did not have any significant difference in the number of family members and duration of menstrual cycle with dysmenorrhea.

On the other hand, a significant positive correlation was observed between dysmenorrhea in terms of menarche age $(\mathrm{P}<0.001)$, aggravating and palliative factors of menstrual pain $(\mathrm{P}<0.001, \mathrm{P}<0.001$, respectively), red meat consumption $(\mathrm{P}<0.001)$, dairy products $(\mathrm{P}<0.001)$, regular exercise $(\mathrm{P}<0.001)$, and sleep duration $(\mathrm{P}<0.001)$. Also, a significant negative correlation was found between dysmenorrhea in terms of duration of menstrual pain $(\mathrm{P}<0.001)$ and bleeding $(\mathrm{P}<0.001)$; BMI $(\mathrm{P}<0.001)$; age $(\mathrm{P}<0.001)$; birth order $(\mathrm{P}=0.022)$; consumption of dried fruit (dried figs, raisins, all kinds of oilseeds such as pistachio and almond, etc.) $(\mathrm{P}<0.001)$, fish $(\mathrm{P}<0.001)$ and pickles $(\mathrm{P}<0.001)$; having breakfast $(\mathrm{P}<0.001)$; bed time $(\mathrm{P}<0.001)$; and wake-up time $(\mathrm{P}<0.001)$. The prevalence of dysmenorrhea in this study was $93.7 \%$ (mild $15.3 \%$, moderate $45.6 \%$, and severe dysmenorrhea 39.1\%). (Table 3)

\section{Discussion}

This epidemiologic study on dysmenorrhea specifically targeted female junior high-school students (aged 15-18 years). Dysmenorrhea in this study was defined as experiencing menstrual pain.

Table 1. Relationship between sociodemographic factors and intensity of menstrual pain

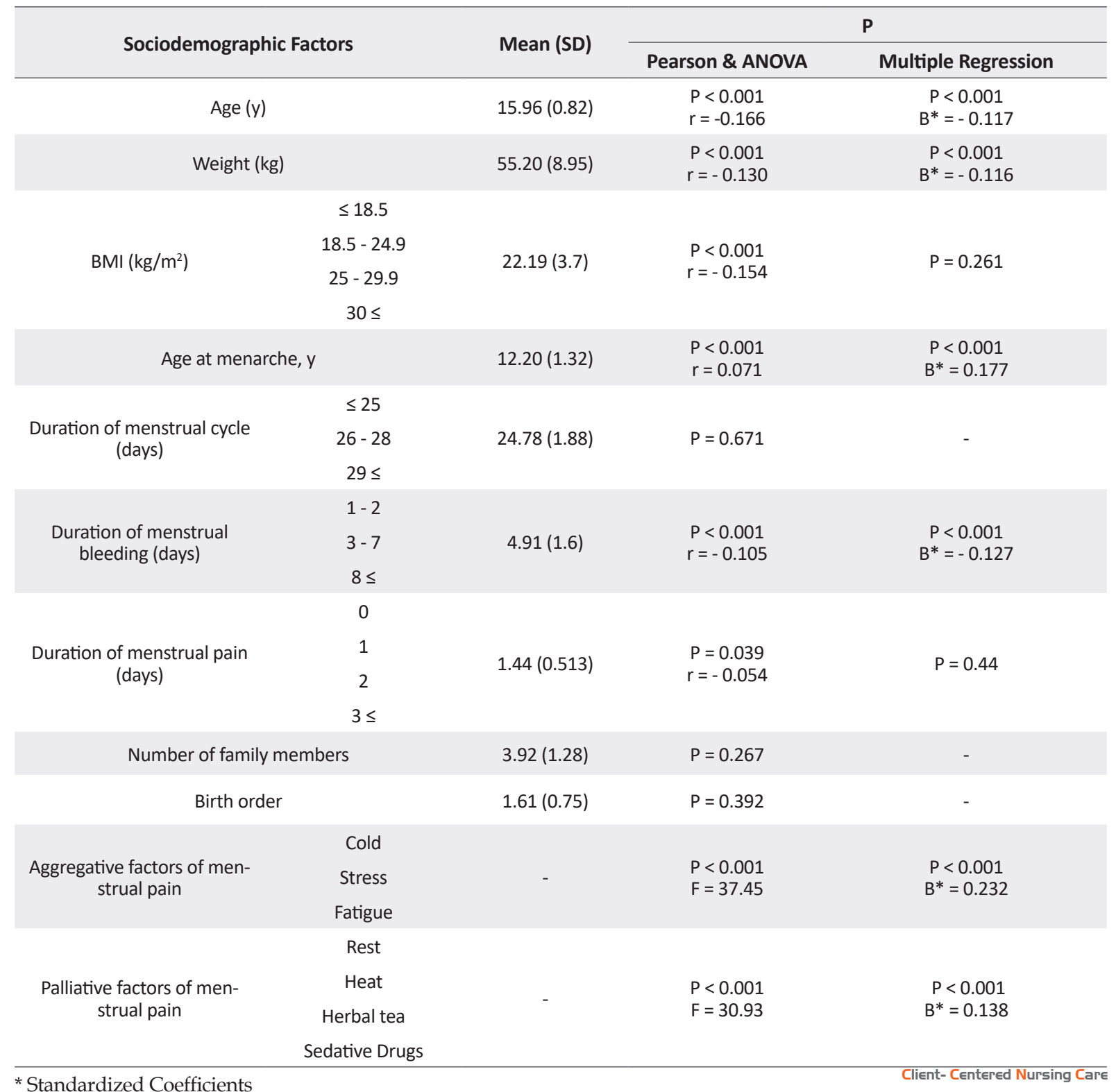


Table 2. Relationship between the sleep status, average food consumption, and intensity of menstrual pain

\begin{tabular}{|c|c|c|c|c|}
\hline \multirow{2}{*}{\multicolumn{2}{|c|}{ Sleep Status and Food Consumption }} & \multirow{3}{*}{$\begin{array}{c}\text { Code } \\
0\end{array}$} & \multicolumn{2}{|r|}{$\mathbf{P}$} \\
\hline & & & \multirow{4}{*}{$\begin{array}{l}\text { ANOVA } \\
\begin{array}{l}P<0.001 \\
F=16.19\end{array}\end{array}$} & \multirow[t]{2}{*}{ Multiple Regression } \\
\hline \multirow{3}{*}{ Red meat consumption (per week) } & 1 & & & \\
\hline & 2 & 1 & & $\begin{array}{l}P<0.001 \\
B^{*}=0.129\end{array}$ \\
\hline & $>2$ & 2 & & \\
\hline \multirow{3}{*}{$\begin{array}{l}\text { Consumption of dried fruit (Dried figs, } \\
\text { raisins, all kinds of oilseeds such as } \\
\text { pistachios and almonds, etc.) (A week) }\end{array}$} & 1 & 0 & \multirow{3}{*}{$\begin{array}{l}P<0.001 \\
F=29.45\end{array}$} & \multirow{3}{*}{$\begin{aligned} P & <0.001 \\
B^{*} & =-0.145\end{aligned}$} \\
\hline & 2 & 1 & & \\
\hline & $>2$ & 2 & & \\
\hline \multirow{4}{*}{ Fish consumption (Per week) } & 0 & 0 & \multirow{4}{*}{$\begin{array}{l}P<0.001 \\
F=17.01\end{array}$} & \multirow{4}{*}{$P=0.127$} \\
\hline & 1 & 1 & & \\
\hline & 2 & 2 & & \\
\hline & $>2$ & 3 & & \\
\hline \multirow{4}{*}{ Dairy products consumption } & Daily & 0 & \multirow{4}{*}{$\begin{array}{l}P<0.001 \\
F=14.11\end{array}$} & \multirow{4}{*}{$P=0.672$} \\
\hline & Almost daily & 1 & & \\
\hline & 3 or 4 times a week & 2 & & \\
\hline & $<3-4$ times a week & 3 & & \\
\hline \multirow{4}{*}{ Pickles consumption } & Daily & 0 & \multirow{4}{*}{$\begin{array}{l}P<0.001 \\
F=21.60\end{array}$} & \multirow{4}{*}{$\begin{aligned} P & <0.001 \\
B^{*} & =-0.197\end{aligned}$} \\
\hline & Almost daily & 1 & & \\
\hline & 3 or 4 times a week & 2 & & \\
\hline & $<3-4$ times a week & 3 & & \\
\hline \multirow{3}{*}{ Regular exercise } & Daily & 0 & \multirow{3}{*}{$\begin{array}{c}P<0.001 \\
F=146.69\end{array}$} & \multirow{3}{*}{$\begin{array}{c}P<0.001 \\
B^{*}=0.303\end{array}$} \\
\hline & 3 or 4 times a week & 1 & & \\
\hline & $<3-4$ times a week & 2 & & \\
\hline \multirow{3}{*}{ Having breakfast } & Never & 0 & \multirow{3}{*}{$\begin{array}{l}P<0.001 \\
F=93.82\end{array}$} & \multirow{3}{*}{$\begin{array}{c}P<0.001 \\
B^{*}=-0.238\end{array}$} \\
\hline & Sometimes & 1 & & \\
\hline & Every day & 2 & & \\
\hline \multirow{3}{*}{ Bed time } & 12 and after that & 0 & \multirow{3}{*}{$\begin{array}{l}P<0.001 \\
F=17.45\end{array}$} & \multirow{3}{*}{$\begin{aligned} P & =0.03 \\
B^{*} & =0.072\end{aligned}$} \\
\hline & $11-12$ & 1 & & \\
\hline & 11 and before that & 2 & & \\
\hline \multirow{3}{*}{ Awake time } & 6 and before that & 0 & \multirow{3}{*}{$\begin{array}{l}P<0.001 \\
F=23.44\end{array}$} & \\
\hline & $7-6$ & 1 & & $\begin{array}{c}P<0.001 \\
B^{*}=-0.113\end{array}$ \\
\hline & 7 and after that & 2 & & \\
\hline & $<6$ & 0 & & \\
\hline Sleen duration (hours) & $7-6$ & 1 & $P<0.001$ & $P=0.01$ \\
\hline Sleep auranon (nours) & $8-7$ & 2 & $F=18.19$ & $B^{*}=0.08$ \\
\hline & 8 and more & 3 & & \\
\hline
\end{tabular}

* Standardized Coefficients

Client- Centered Nursing Care

Moderate or severe dysmenorrhea requires relief and prevention, which accounted for $84.7 \%$ of the menstrual pain in this research. The prevalence of moderate to severe dysmenorrhea ranges from $46.8 \%$ to $75 \%$ in several studies, which is lower than the rate investigated in this report and could be attributed to our older study population, because some studies have shown that the preva- lence of dysmenorrhea increases with age (Kazama et al. 2015; Pitangui et al. 2013; Rigon et al. 2012).

Exercise is generally believed to relieve the symptoms of dysmenorrhea. One plausible explanation is that aerobic exercise is effective through shunting the blood flow away from the viscera, resulting in less blood con- 
Table 3. Prevalence of dysmenorrhea

\begin{tabular}{ccccc}
\hline Dysmenorrhea Features & & No. (\%) & (\%) \\
\hline & 0 & $92(6.2)$ & 6.2 \\
Pain days & 1 & $629(42.6)$ & 93.7 \\
& 2 & $625(42.4)$ & 15.3 \\
Severity of pain & Mild & $225(15.3)$ & $673(45.6)$ & 84.7 \\
\hline
\end{tabular}

Client- Centered Nursing Care

gestion in the pelvic area during the menstrual phase (Daley 2008). Kazama et al. (2015) found that higher levels of sports activities were significantly related to a lower prevalence of severe dysmenorrhea (adjusted $\mathrm{P}$ for trend $=0.045$ ).

Similar to our results, Gagua, Tkeshelashvili and Gagua (2012) and Kazama et al. (2015) reported that a short sleeping time was associated with primary dysmenorrhea in adolescents. Indeed, dysmenorrhea itself might disturb normal sleep (Gagua, Tkeshelashvili \& Gagua 2012; Kazama et al., 2015). Also, sleeping late and waking up early is associated with more severe menstrual pain; according to the present study, people who experience severe menstrual pain need to sleep more than 8 hours.

Our findings are consistent with the results of the studies conducted by Fujiwara and Nakata (2010) and Kazama et al. (2015) stating that female college students who skip breakfast have a significantly higher degree of dysmenorrheal symptoms than those who eat breakfast. In the present study, about $8.7 \%$ of the participants did not eat breakfast every day. While the mechanisms underlying the adverse effects of skipping a meal are unclear, they may be related to the inadequate intake of certain foods (Fujiwara \& Nakata 2010; Kazama et al. 2015). In addition, low intake of dairy products and red meat according to this research may relieve dysmenorrhea, which is consistent with previous reports (Abdul-Razzak et al. 2010).

Molazem et al. (2009) investigated the epidemiology of dysmenorrhea and its relationship with food and exercise habits, and reported a prevalence of $91 \%$ for dysmenorrhea. Moreover, consistent with the present study, he showed a significant negative association between the consumption of fish and dried fruits and a significant positive relationship between the consumption dairy products and red meat with dysmenorrhea. However, in contrast to our results, he reported a significant positive relationship between the consumption of pickles and dysmenorrhea (Molazem et al. 2011).

However, some research studies, contrary to the present study, did not find any significant relationship between dysmenorrhea, body weight, and BMI, but supported the relationship between exercise and menstrual pain (Haidari et al. 2011; Ezbarami, Mirzaei \& Esfarjani 2014). According to the results of studies on reproductive problems (Yari et al. 2015) and menstrual disorders of students, attention to the needs of them should be the main objectives of reproductive health.

Dysmenorrhea is highly prevalent and may be related to lifestyle factors among female high-school students. High school teachers, particularly those in charge of health education, should be aware of these facts and provide the proper information for curing those suffering from dysmenorrhea, absentees, and those experiencing problems in school life due to the symptoms.

The present study had some limitations. We used a crosssectional design which cannot determine the exact causal relationships. In the context of this study, for example, the identified risk factors may have been caused by dysmenorrhea symptoms. Conducting longitudinal studies to address this issue is suggested.

\section{Ethical Considerations}

\section{Compliance with ethical guidelines}

The Ethics Committee affiliated with Urmia University of Medical Sciences approved this study research pro- 
posal (1394-01-42-2017). Informed consent was obtained from the students who agreed to participate in the study.

Funding

This research was funded by Urmia University of Medical Sciences.

\section{Conflict of interest}

The authors declared no conflict of interest.

\section{Acknowledgements}

The authors would like to express their gratitude to the participants who without their participation, the production of this paper would be impossible

\section{References}

Abdul-Razzak, K. K., et al., 2010. Influence of dietary intake of dairy products on dysmenorrhea. Journal of Obstetrics and Gynaecology Research, 36(2), pp. 377-83. [DOI:10.1111/j.14470756.2009.01159.x] [PMID]

Alonso, C. \& Coe, C. L., 2001. Disruptions of social relationships accentuate the association between emotional distress and menstrual pain in young women. Health Psychology, 20(6), pp. 411-6. [DOI:10.1037/0278-6133.20.6.411] [PMID]

Azimi, P. \& Abrishami, R., 2018. Comparison of the effects of crocus sativus and mefenamic acid on primary dysmenorrhea. Journal of Pharmaceutical Care, 4(4-3), pp. 75-8.

Barnard, N. D., et al., 2000. Diet and sex-hormone binding globulin, dysmenorrhea, and premenstrual symptoms. $O b$ stetrics \& Gynecology, 95(2), pp. 245-50. [DOI:10.1016/S00297844(99)00525-6]

Beiranvand, S. P., et al., 2016. The effect of Crocus sativus (saffron) on the severity of premenstrual syndrome. European Journal of Integrative Medicine, 8(1), pp. 55-61. [DOI:10.1016/j. eujim.2015.06.003]

Chen, H. M. \& Hu, H. M., 2018. Randomized trial of modified stretching exercise program for menstrual low back pain. Western Journal of Nursing Research, p. 0193945918763817. [DOI:10.1177/0193945918763817]

Daley, A. J., 2008. Exercise and primary dysmenorrhoea. Sports Medicine, 38(8), pp. 659-70. [DOI:10.2165/00007256-20083808000004] [PMID]

French, L., 2008. Dysmenorrhea in adolescents. Pediatric Drugs, 10(1), pp. 1-7. [DOI:10.2165/00148581-200810010-00001] [PMID]

Fujiwara, T. \& Nakata, R., 2010. Skipping breakfast is associated with reproductive dysfunction in post-adolescent female college students. Appetite, 55(3), pp. 714-7. [DOI:10.1016/j.apa pet.2010.08.005] [PMID]
Gagua, T., Tkeshelashvili, B. \& Gagua, D., 2012. Primary dysmenorrhea: Prevalence in adolescent population of Tbilisi, Georgia and risk factors. Journal of the Turkish-German Gynecological Association, 13(3), pp.162-8. [DOI:10.5152/jtgga.2012.21] [PMID] [PMCID]

Haidari, F., et al., 2011. [Prevalence and severity of primary dysmenorrhea and its relation to anthropometric parameters (Persian)]. Journal of Hayat, 17(1), pp. 70-7.

Harlow, S. D. \& Campbell, O. M., 2004. Epidemiology of menstrual disorders in developing countries: A systematic review. BJOG: An International Journal of Obstetrics \& Gynaecology, 111(1), pp. 6-16 [DOI:10.1111/j.1471-0528.2004.00012.x] [PMID]

Kazama, M., Maruyama, K. \& Nakamura, K., 2015. Prevalence of dysmenorrhea and its correlating lifestyle factors in Japanese female junior high school students. The Tohoku Journal of Experimental Medicine, 236(2), pp. 107-13. [DOI:10.1620/ tjem.236.107] [PMID]

Latthe, P., et al., 2006. Factors predisposing women to chronic pelvic pain: Systematic review. BMJ, 332(7544), pp. 749-55. [DOI:10.1136/bmj.38748.697465.55] [PMID] [PMCID]

Mojarrad Ezbarami, S., Mirzaei, B. \& Esfarjani, F., 2014. [Comparison the prevalence and severity of dysmenorrhea among athletes and non-athletes and its relation with body composition (Persian)]. Arak Medical University Journal, 16(11), pp. 80-8.

Moghadam, Z. B., et al., 2016. The effect of Valerian root extract on the severity of pre menstrual syndrome symptoms. Journal of Traditional and Complementary Medicine, 6(3), pp. 309-15 [DOI:10.1016/j.jtcme.2015.09.001]

Molazem, Z., et al., 2011. Epidemiology of dysmenorrhea with dietary habits and exercise. Zahedan Journal of Research in Medical Sciences, 13(3), pp. 41-5.

Pitangui, A. C. R., et al., 2013. Menstruation disturbances: Prevalence, characteristics, and effects on the activities of daily living among adolescent girls from Brazil. Journal of Pediatric and Adolescent Gynecology, 26(3), pp. 148-52. [DOI:10.1016/j. jpag.2012.12.001] [PMID]

Rigon, F., et al., 2012. Menstrual pattern and menstrual disorders among adolescents: An update of the Italian data. Italian Journal of Pediatrics, 38(1), p. 38. [DOI:10.1186/1824-7288-38-38] [PMID] [PMCID]

Sultan, C., Gaspari, L. \& Paris, F., 2012. Adolescent dysmenorrhea. In C. Sultan (ed.), Pediatric and adolescent gynecology: Evidence-based clinical practice. Basel: Karger Publishers.

Tonini, G., 2002. Dysmenorrhea, endometriosis and premenstrual syndrome. Minerva Pediatrica, 54(6), pp. 525-38. [PMID]

Travers, M., et al., 2018. Exercise-induced hypoalgesia in women with varying levels of menstrual pain. Scandinavian Journal of Pain, 18(2), pp. 303-10. [DOI:10.1515/sjpain-2018-0020]

Unsal, A., et al., 2010. Prevalence of dysmenorrhea and its effect on quality of life among a group of female university students. Upsala Journal of Medical Sciences, 115(2), pp. 138-45. [DOI:10.3109/03009730903457218] [PMID] [PMCID]

Wang, L., et al., 2004. Stress and dysmenorrhoea: A population based prospective study. Occupational and Environmental Medicine, 61(12), pp. 1021-6. [DOI:10.1136/oem.2003.012302] [PMID] [PMCID] 
Weissman, A. M., et al., 2004. The natural history of primary dysmenorrhoea: A longitudinal study. BJOG: An International Journal of Obstetrics \& Gynaecology, 111(4), pp. 345-52. [DOI:10.1111/j.1471-0528.2004.00090.x] [PMID]

Yari, F., et al., 2015. Sexual and reproductive health problems of female university students in Iran: A qualitative study. Global Journal of Health Science, 7(4), 278-85. [DOI:10.5539/gjhs. v7n4p278] [PMID] [PMCID] 